This document is the accepted manuscript version of the following article:

Teze1, A. 0., Sunde, S., Gómez-Cámer, J. L., Novák, P., \& Svensson, A. M. (2020). Effect of a boron based anion receptor on graphite and LiFePO4 electrodes. Journal of the Electrochemical Society, 167(2), 020525 (10 pp.). https://doi .org/10.1149/1945-7111/ab68c5

\title{
Effect of a Boron Based Anion Receptor on Graphite and $\mathrm{LiFePO}_{4}$ Electrodes
}

Ahmet Oguz Tezel ${ }^{1,2}$, Svein Sunde ${ }^{1}$ Juan Luis Gómez-Cámer ${ }^{2,3}$, Petr Novák², Ann Mari Svensson ${ }^{1}$

${ }^{1}$ Norwegian University of Science and Technology, Department of Materials Science and Engineering, N-7491, Trondheim, Norway

${ }_{2}^{2}$ Paul Scherrer Institute, Electrochemistry Laboratory, CH-5232 Villigen PSI, Switzerland

${ }^{3}$ Departamento de Química Inorgánica e Ingeniería Química, Universidad de Córdoba

\section{Abstract}

The effect of a boron based anion receptor, tris (hexafluoroisopropyle) borate (THFIPB), on the electrochemistry of graphite was investigated in $1 \mathrm{M} \mathrm{LiPF}_{6}$ in ethylene carbonate/dimethyl carbonate (EC/DMC, 1:1 by weight) electrolyte. A stable solid electrolyte interphase (SEI) and more porous SEI layer, as observed by SEM, was formed in the presence of THFIPB. The rate capability of the graphite electrode was improved due to THFIPB addition. Capacity measurements performed for more than 200 cycles showed that the capacity retention was significantly improved due to THFIPB addition. Cycling experiments at $0^{\circ} \mathrm{C}$ and $50^{\circ} \mathrm{C}$ demonstrated that THFIPB is compatible with operations in an extended temperature window, and improved practical specific charge was demonstrated. Improved performance was also demonstrated for $\mathrm{LiFePO}_{4}$ (LFP) cathodes in combination with THFIPB containing electrolyte. However, in graphite-LFP full cells, the use of the THFIPB containing electrolyte resulted in a slightly lower capacity, attributed to the higher irreversible charge "loss" and corresponding limitations of the Li-inventory in the balanced cell.

\section{Introduction}

The Li-ion battery technology is the preferred energy storage technology for a wide range of applications such as electrical vehicles (EV) and portable electronics, due to the high specific energy and power [1]. The need for further improvements with respect to specific energy and power, lower cost, and improved lifetime has stimulated current research on new electrode materials and electrolytes. Graphite is the dominant material for commercial anodes [2] and Li-oxides like $\mathrm{LiCoO}_{2}$, $\mathrm{LiNi}_{x} \mathrm{Mn}_{\mathrm{y}} \mathrm{Co}_{z} \mathrm{O}_{2}, \mathrm{LiFePO}_{4}$ and $\mathrm{LiMn}_{2} \mathrm{O}_{4}$ are the major cathode materials. Substituting graphite is a 
challenging task due to its unique qualities, thus, improvement of graphite electrodes is still highly actual. Graphite has a low $\mathrm{Li}^{+}$intercalation potential (close to the $\mathrm{Li} / \mathrm{Li}^{+}$redox potential), high electronic conductivity, and demonstrates structural integrity upon $\mathrm{Li}^{+}$uptake. However, graphite intercalates lithium at potentials below the electrochemical reduction potential of commercial solvents and electrolyte salt species. Therefore, both solvents and electrolyte salts decompose at the graphite/electrolyte interphase before $\mathrm{Li}^{+}$intercalation. The decomposition products, mainly formed during the first cycle, result in a surface film known as a solid electrolyte interphase (SEI). The SEI consists of a mosaic of individual phases $[2,3]$, some of which are electronic insulators. The SEI prevents further electrolyte decomposition, while allowing $\mathrm{Li}^{+}$transport [4]. The structure of the SEI is generally believed to be "mosaic", with an inner layer dominated by inorganic components, and an outer layer with predominantly organic components. There is, however, no simple correlation between composition, thickness, and resistance of an SEI layer.

The interphasial chemistry, i.e., the formation and properties of the SEI [5] has a large impact on the electrochemical performance of graphite anodes. For graphite, $\mathrm{Li}^{+}$intercalation is preceded by two kinetically limited processes; (1) $\mathrm{Li}^{+}$desolvation at the SEI-electrolyte interface and (2) $\mathrm{Li}^{+}$transport across the SEI [6]. The former is the result of ion-solvent interactions and can be tailored by using appropriate electrolyte additives. The latter is controlled by the SEI, whose formation path and stability are also affected by the electrolyte.

Optimization of electrolyte mixtures is a complex task. Consideration of transport properties, electrochemical stability, temperature range, safety features, and compatibility with both anode and cathode materials is necessary and requires compromises [7]. Therefore, an electrolyte additive that improves both electrolyte performance and SEI chemistry is desirable. Anion receptors (AR) are promising candidates in this context. They function as anion-binding agents, promote salt dissolution, and reduce ion-pairs, therefore increase the ionic conductivity $[8,9]$. ARs with many different chemistries and structures were studied in the past. The library of ARs spans from aza-ethers to boron and phosphor based receptors. Among them boron-based receptors have received the greatest interest for applications in Li-ion batteries. Various groups synthesized boron based anion receptors and tested 
them with various lithium salts $[8,9,10,11]$. They observed a general increase in ionic conductivity. A comparative study of two ARs, namely, tris(pentafluorophenyl)borane (TPFPB) and tris(pentafluorophenyl)borate (TPFBO) showed that both additives improved the ionic conductivity of various lithium salts even in the highly viscous PC-EC-DMC solvent [8].

It should be noted that both the amount and the type of AR are important factors on the cell performance; some may improve capacity retention and yield higher reversible capacity, while others deteriorate the cell performance $[12,13]$. The presence of AR in the electrolyte will affect the SEI layer. Inorganic components of the SEI that are in contact with electrolyte might be attacked and dissolved by the anion receptor. The LiF content in the SEI has been reported to decrease on TPFPB and 2-(pentafluorophenyl)-tetrafluoro-1,3,2-benzodioxaborole (PFPTFBB) addition [12, 14, 15]. On the contrary, Sun et al. [16] showed that a stable SEI was formed during the first cycle on a meso carbon micro beads $(\mathrm{MCMB})$ anode upon addition of $0.1 \mathrm{M}$ TPFPB in $1 \mathrm{M} \mathrm{LiPF}_{6}, \mathrm{EC}: \mathrm{DMC}$ (1:1 wt.\%). Moreover, in this work, it was shown that TPFPB did not attack the SEI even after a heat treatment at $50^{\circ} \mathrm{C}$, as was confirmed by cyclic voltammetry and electrochemical cycling of the electrodes [16]. Thermal stability of the SEI can also be modified by AR addition. According to a differential scanning calorimetry analysis (DSC), onset temperature for exothermic SEI decomposition was shifted from $60-80^{\circ} \mathrm{C}$ to $140-160^{\circ} \mathrm{C}$ in $0.2 \mathrm{M}$ TPFPB, while the SEI decomposed at a lower temperature than the standard electrolyte in $0.8 \mathrm{M}$ TPFPB [14]. A concentration of $0.8 \mathrm{M}$ TPFPB was found to be too high, as it also caused excessive SEI formation [14].

Anion receptors, in general, are known to catalyze the EC reduction, possibly through the generation of $\mathrm{PF}_{5}$ which acts as a catalyst for ring opening polymerization of EC, as described by Sloop et al. [17]. When an anion receptor is added to a $\mathrm{LiPF}_{6}$ solution, it either binds the $\mathrm{PF}_{6}^{-}$ion (eq.1) or captures a $\mathrm{F}^{-}$from it (eq.2), the latter generating $\mathrm{PF}_{5}$ in the electrolyte.

$$
\begin{aligned}
& \mathrm{PF}_{6}^{-}+\mathrm{AR} \rightarrow \mathrm{PF}_{6}^{-}-\mathrm{AR} \\
& \mathrm{PF}_{6}^{-}+\mathrm{AR} \rightarrow \mathrm{AR}-\mathrm{F}^{-}+\mathrm{PF}_{5}
\end{aligned}
$$


The most widely studied anion receptor as additive for Li-ion batteries is TPFPB [12, 14, 16], for which improved performance has been demonstrated, provided that the concentration is controlled. Qin et al [13] demonstrated a correlation between the localization of the lowest unoccupied molecular orbital (LUMO) and the electrochemical performance (i.e. localization of the LUMO on the boron center was found to be beneficial). In this work, based on results from electrochemical cycling of full cells, impedance spectra, as well as the advantageous localization of the LUMO obtained from the theoretical calculations, THFIPB was identified as a promising anion receptor additive [13]. There were, however, no details provided regarding effects on the individual electrodes.

The free energy change when THFIPB binds to $\mathrm{F}^{-}$ion has been shown to be negative in previous works $[18,10]$. Therefore we may expect a catalyzed EC reduction in the presence of THFIPB due to the generation of $\mathrm{PF}_{5}$ as described by equation 2. Similar conclusions were drawn for TPFPB- $\mathrm{PF}_{6}^{-}$ interactions, where it was experimentally confirmed that the fluorine was transferred to the anion receptor [19].

The research on anion receptors and their effect on graphitic anodes is intriguing but still incomplete. In view of the promising results previously obtained with the THFIPB [13], in respect to its high $\mathrm{F}^{-}$ affinity $[10,18]$, we investigate here the effect on $\mathrm{Li}^{+}$intercalation behavior in $1 \mathrm{M} \mathrm{LiPF}_{6}$ in EC:DMC (1:1 wt. \%) into a graphitic anode for various (dis)charge rates and temperatures. Performance of the graphite during extended cycling is discussed and correlated with SEI morphology, with the aid of post-mortem scanning electron microscopy (SEM) images. Electrochemical techniques are used to show the differences in SEI formation mechanism and conductivity of the electrolytes. Effect of concentration of the THFIPB in the electrolyte is also investigated. Comparison is made to other electrolytes containing $\mathrm{LiClO}_{4}$ to identify possible causes (or mechanisms) of the observed improvements and to highlight the role of the anion. The electrolytes containing THFIPB are evaluated also in half cells with $\mathrm{LiFePO}_{4}$ (LFP), as well as in graphite-LFP full cells. 


\section{Experimental}

Anode half-cell tests - Graphitic anodes made from SLP30 (IMERYS Graphite \& Carbon) were used for all experiments. The composite electrode sheets were prepared by coating copper foil via doctor blading. A slurry of active material (SLP30), polyvinylidene difluoride (Kynar® HSV 900), and Super P conductive filler (IMERYS Graphite \& Carbon) with a weight ratio of 80:10:10, respectively, was prepared in N-methyl pyrrolidone (NMP; Sigma-Aldrich). The loading of the graphite electrode was around $4.5 \mathrm{mg} / \mathrm{cm}^{2}$. The electrodes were $1.5 \mathrm{~cm}$ in diameter. Li foil served as both counter and reference electrode. A monolayer polypropylene separator (CELGARD 2400) soaked with a commercial electrolyte, LP30 (1 M LiPF 6 in EC/DMC (1:1 weight\%), BASF) was sandwiched between working and counter electrode. The water content of the electrolyte was measured by Karl Fischer titration, and confirmed to be below 20 ppm. THFIPB (TCI Europe, >95\% purity) was added at 0.025 (AR25), 0.075 (AR75), and 0.1 (AR100) molar concentrations. The molecular structure of THFIPB is given in Figure 1.

The cells were assembled in an argon-filled dry box with a water and oxygen level of $<1 \mathrm{ppm}$. Electrochemical measurements were conducted using a computer controlled cell capture system (CCCC, Astrol Electronic AG). Galvanostatic lithiation/delithiation was performed in a potential range of $0.005-1.5 \mathrm{~V}$. (vs. $\mathrm{Li}^{\left.-\mathrm{Li}^{+}\right)}$. All cells were subjected to $10 \mathrm{~A} / \mathrm{kg}(\sim \mathrm{C} / 37)$ and $50 \mathrm{~A} / \mathrm{kg}(\mathrm{C} / 7)$ specific formation currents, respectively, during the first and second cycle. Here, C-rate is with respect to $372 \mathrm{Ah} / \mathrm{kg}$. A potentiostatic step was included at the end of each half cycle to ensure full lithiation/delithiation. For the first lithiation, this involved reducing the specific current to $5 \mathrm{~A} / \mathrm{kg}$ and for the subsequent cycles the step was applied until the specific current dropped to $10 \%$ of the initial value. Linear sweep voltammetry (LSV) was performed in 3-electrode cells with a Li reference and counter electrode.

Cathode half-cell and full-cell test-Commercial $\mathrm{LiFePO}_{4}$ and graphite electrode sheets fabricated from SLP30 with areal capacity of $1.1 \mathrm{mAh} / \mathrm{cm}^{2}$ were used for all experiments. Electrode disks with a diameter of $15 \mathrm{~mm}$ and $14 \mathrm{~mm}$ (anode/cathode) were cut and placed in a vacuum oven at $100^{\circ} \mathrm{C}$ 
overnight and then transferred to an argon-filled glove box for cell assembly. A Celgard 2400 soaked with LP30 $(150 \mu \mathrm{L})$ was used as separator. 2032 type coin cells were used for electrochemical tests. All cells were subjected to ten galvanostatic charge/discharge cycles at $1 \mathrm{C}$ rate. For rate tests, charging was always conducted at $1 \mathrm{C}$ rate with a potentiostatic step included at the end to ensure full charging, while the discharge rate was increased after 5 cycles at each rate. Cut-off potentials were chosen to be $4.2 \mathrm{~V}-2.5 \mathrm{~V}$ and $3.5 \mathrm{~V}-2.4 \mathrm{~V}$ for half-cells and full-cells respectively. A constant current - constant voltage (CCCV) charging protocol was used. For electrodes subject to swapping (i.e. cycling in half cells with different electrolytes), the electrodes were rinsed with DMC and dried in argon atmosphere. Area specific impedance (ASI) was determined according to a modified testing protocol [20];

$1 \mathrm{C} / 10$ cycle

$\mathrm{C} / 3$ charge followed by $1 \mathrm{C}$ discharge

$\mathrm{C} / 3$ charge with a 1 hour rest

$\mathrm{C} / 3$ discharge to extract $0.1 \mathrm{C}$ followed by 1 hour rest

$2 \mathrm{C}$ discharge for 10 s pulse followed by a 40 s rest

$1.5 \mathrm{C}$ charge (10s) pulse followed by a $40 \mathrm{~s}$ pulse

Electrochemical impedance spectroscopy (EIS) was performed in a two-electrode cell design using a VMP3 potentiostat in a temperature controlled chamber. A potential perturbation amplitude of $10 \mathrm{mV}$ was applied with frequencies between $100 \mathrm{kHz}$ and $100 \mathrm{mHz}$.

Post-mortem SEM micrographs were taken using the Carl Zeiss microscope Supra55VP. Electrodes were extracted from cells in delithiated state, washed with DMC, and dried in an argon environment before being transferred to SEM in a hermetically sealed transfer chamber. Depending on the particular case, an acceleration voltage between $2 \mathrm{kV}$ and $4 \mathrm{kV}$ was applied. 


\section{Results and discussion}

Figure 2 shows the first lithiation/delithiation profile for Li/SLP30 half cells in LP30, AR25, AR75, and AR100 electrolytes, obtained at a rate of C/37. Several potential plateaus (at ca. $800 \mathrm{mV}, 170 \mathrm{mV}$, $81 \mathrm{mV}$, and $57 \mathrm{mV}$ ) can be seen on the graphs, corresponding to electrochemical reactions at the anode, including lithiation/delithiation and also various side reactions. The plateau at ca. $0.8 \mathrm{~V}$ is typically attributed to EC reduction and SEI formation. The plateaus at $170 \mathrm{mV}, 81 \mathrm{mV}$, and $57 \mathrm{mV}$ are characteristic for the staged intercalation of $\mathrm{Li}^{+}$that finally leads to $\mathrm{LiC}_{6}$. Additional electrochemical activity starts near $1.5 \mathrm{~V}$ on THFIPB addition. Little is known about the charge consuming reactions occurring at potentials higher than $1.0 \mathrm{~V}$, but decomposition of water was shown to occur negative to $1.9 \mathrm{~V}$ [21]. In a recent study, the SEI formation process was characterized by a range of techniques, and at $1.3 \mathrm{~V}$, both salt and EC decomposition products, including lithium ethylene dicarbonate and $\mathrm{LiF}$, were detected [22]. Chen and Amine [12] also observed a peak at around $1.1 \mathrm{~V}$ which they attributed to anion decomposition, as it was shifted to a higher potential upon increase in concentration of the salt.

An extension of the $0.8 \mathrm{~V}$ plateau is observed upon addition of THIFPB (Figure 2). Adding THFIPB to the electrolyte shifts all plateaus to more positive values by (ca. $25 \mathrm{mV}$ ), however, the plateaus occur almost at the same potentials during delithiation. Contrary to the first intercalation, the potential profiles for the second intercalation are overlapping in both of the electrolytes (not shown). Thus, the addition of THFIPB decreases the additional overpotential for intercalation only in the first charge. This indicates that the shift in potential plateaus observed in the first cycle is related to differences in SEI formation kinetics, and not to differences in electrolyte conductivity or kinetics of the Li counterelectrode.

It is well known that the composition of SEI is determined by the competing irreversible reductions of solution species, mainly during the first lithiation. Thus, SEI formed with and without AR will be different, as evident from the comparison of irreversible capacities (called often irreversible capacity "loss", ICL) for the first and the second cycles, which are $26 \%$ and $2 \%$ with LP30 and $32 \%$ and 3\% 
with AR25 electrolyte, respectively. It should be noted that the specific charge is calculated with respect to the amount of active material in the electrode, and that the contribution from the carbon black (in this case $10 \mathrm{wt} \%$ ) is not included. In cycles following the formation cycles, the irreversible charge "loss" drops significantly and the charge "loss" is approximately zero for both electrolytes. This demonstrates that there is a protective and stable SEI layer also in the presence of the THFIPB. The difference between the irreversible charge of the LP30 containing cell (26\%) and the AR25 containing cell (32\%) is mainly related to the charge consumed in the region 1.5-0.7 V. This provides a possible explanation for the observed intercalation potential shift. We observed a positive shift in the intercalation potential plateaus during the first lithiation with THFIPB addition (Figure 2). The total specific current $(10 \mathrm{~A} / \mathrm{kg})$ that passes the anode can be defined as the sum of the partial currents of the competing reduction reactions. This requires any increase in EC reduction current to be counterbalanced by a decrease in Li-intercalation partial current when cells are lithiated galvanostatically. Consequently, potential plateaus representing Li-intercalation in the first lithiation process may be shifted to more positive potentials on THFIPB addition, because lowering the current density at which the intercalation proceeds should lower the overpotential. Upon delithiation, and for the subsequent cycles, these shifts are not observed. Therefore we propose that the assumed catalytic effect of $\mathrm{PF}_{5}$ on the EC reduction could be the origin of the observed potential shift in the first lithiation.

To further support the above argument, we cycled the cells in electrolytes with various THFIPB molarities. Figure 2 is a plot of electrode potential of graphite electrodes vs. specific charge in LP30, AR25, AR75, and AR100 containing electrolytes. It is seen that the noticeable reduction starts at about 1.5 V upon THFIPB addition and continues until the appearance of EC reduction plateau at $0.8 \mathrm{~V}$, whereas much less electrochemical activity is observed down to $1.2 \mathrm{~V}$ in LP30 electrolyte. The electrochemical activity positive to $1 \mathrm{~V}$ is tentatively explained in terms of reduction of impurities, salts and/or surface groups. Similarly, the EC reduction plateau seen at $0.8 \mathrm{~V}$ in LP30 is displaced to more positive values with increasing THFIPB molarity. The intercalation plateaus are also shifted to more positive potentials when THFIPB is added, however, they seem to be independent of THFIPB 
molarity and remain at the same potential for all three THFIPB molarities tested. The high frequency parts of electrochemical impedance spectra are plotted in Figure 3. From these, the ohmic losses in LP30 and AR25 based cells due to the electrolyte resistance under the $10 \mathrm{~A} / \mathrm{kg}(\sim 0.05 \mathrm{~mA})$ formation current were estimated to be 0.18 and $0.13 \mathrm{mV}$, respectively, and hence cannot account for the observed 25-30 mV shift. Therefore we conclude that the established correlation between the EC reduction potential and the THFIPB molarity cannot be taken as a mere reflection of changes in electrolyte conductivity but rather as a change in EC reduction mechanism on THFIPB addition. Due to the excessive SEI formation when more THFIPB is added, the experiments described further below were conducted with $0.025 \mathrm{M}$ solutions, corresponding to ca. $1 \mathrm{wt} \%$.

Linear sweep voltammetry (LSV) curves for graphite electrodes in LP30, AR25, and AR75 with a sweep rate of $10 \mu \mathrm{Vs}^{-1}$ are given in Figure 4. All cells show some badly-defined cathodic processes between 3 and $1 \mathrm{~V}$ (not shown here) that can be ascribed to reduction of $\mathrm{H}_{2} \mathrm{O}$, trace $\mathrm{HF}, \mathrm{PF}_{5}, \mathrm{POF}_{3}$, and oxygen impurities. As a consequence of the low sweep rate, the current response was too noisy to be interpreted over this potential range, and is therefore not elaborated here.

The negative current maxima with peak potentials slightly below $1 \mathrm{~V}$ are typically attributed to solvent (EC) reduction (eq.1). Peak potentials for EC reduction are located at 0.77 and $0.82 \mathrm{~V}$ in AR25 and AR75 respectively, which are more positive than for LP30 (0.75 V).

The peaks below $250 \mathrm{mV}$ are attributed to the staged intercalation in the graphite. The peak potentials shift to more positive values when THFIPB was added. The peaks of the LP30 cells are broad, while upon THFIPB addition peaks are well separated and the current maxima for all the transitions are increasing with increasing THFIPB content of the electrolyte. The LSV results are consistent with the voltage profiles shown in Figure 2, showing the improved intercalation kinetics of the initial lithiation, attributed to the improved Li-ion conductivity of the SEI formed in the presence of THFIPB.

As discussed above, THFIPB addition affects the solvent reduction and subsequent initial intercalation plateaus for the graphite electrode. In order to verify that the effect is the result of THFIPB-PF ${ }_{6}^{-}$interaction, cells were cycled with $1 \mathrm{M} \mathrm{LiClO}_{4}$ dissolved in EC:DMC(1:1 wt.\%) electrolyte (LC30) without THFIPB and with various THFIPB concentrations (Figure 5). It is noted that the electrochemical activity between $\sim 1.6-1.0 \mathrm{~V}$ that was detected with AR25, AR75, and AR100 (Figure 2) is not seen with LC30+0.025M THFIPB and LC30+0.1M THFIPB (Figure 5). 
From the potential profiles as a function of specific charge it is clear that both $\mathrm{EC}$ reduction and $\mathrm{Li}^{+}$ intercalation processes occur at the same potential regardless of THFIPB molarities, in contrast to the results for $\mathrm{LiPF}_{6}$-containing solutions. EC reduction appears at the same intercalation potential for electrolytes with and without THFIPB, in the $\mathrm{LiClO}_{4}$-containing solutions. This is consistent with the assumption that THFIPB promotes the decomposition of $\mathrm{PF}_{6}^{-}$to $\mathrm{PF}_{5}$, which is known to catalyze the EC reduction. In the $\mathrm{LiClO}_{4}$ based electrolyte, $\mathrm{EC}$ reduction is not catalyzed and thus occurs at the same potential for all THFIPB concentrations. It appears, however, that below $0.8 \mathrm{~V}$ and down to the first intercalation step, there is a small increase in the consumed charge upon addition of THIFPB with no shift in the potential, indicating that there is probably also a small catalytic effect of THFIPB on $\mathrm{EC}$ reduction, but considerably lower than for the $\mathrm{LiPF}_{6}$ salt.

Figure 6a is a plot of total specific charge for lithiation (galvanostatic+potentiostatic) as a function of cycle number for the LP30 and AR25 based cells. The corresponding galvanostatic specific charge for lithiation and irreversible charge "loss" are presented in Figure 6b and 6c, respectively. The cells were cycled at $1 \mathrm{C}$ rate $(372 \mathrm{~A} / \mathrm{kg}$ ) for over 200 cycles after the formation cycles (Figure 6a). In the total charge vs. cycle number plot, capacity fading of the electrode indicates loss of active material (either material destruction or loss of electronic contact) as the potentiostatic step ensures full lithiation and/or delithiation irrespective of overpotentials.

Over the entire cycling range, the graphite in the AR25 based cell reaches higher specific charge than in the LP30 based cell. Capacity fade occurs gradually in the LP30 based cell with increasing cycle number. However, the AR25 based cell experiences much less capacity fade, an inflection point occurs around the $50^{\text {th }}$ cycle, and then the cell maintains a constant capacity until the end. The graphite in the LP30 based cell has a specific charge of $275 \mathrm{Ah} / \mathrm{kg}$ after 200 cycles, while in the AR25 based cell it exhibits excellent performance and is capable of delivering $350 \mathrm{Ah} / \mathrm{kg}$ after 200 cycles. It is known that the practical specific charge of graphite anodes decreases with increasing cycle number due to a bunch of phenomena including various side processes. More specifically, there is i) the risk of local overcharge that results in the deposition of metallic lithium and ii) the loss of electronic contact between graphite particles due to full SEI coverage and growth. The former phenomenon is 
known to be especially favored at high charging rates. In a half cell in which there is an "unlimited" source of Li, metallic lithium may be deposited on the graphite surface if the local potential of the graphite surface would be falling below the reversible potential for the $\mathrm{Li} / \mathrm{Li}^{+}$couple [23]. The deposited lithium reacts then with the electrolyte and forms the reaction products of the SEI type which might block the surface.

In figure $6 \mathrm{~b}$ it is seen that the AR25 based cell outperforms the LP30 based cell at all cycle numbers. It should be noted that the galvanostatic mode gives indication on the kinetics of the overall intercalation process. This involves ionic transport in the electrolyte, desolvation of $\mathrm{Li}^{+}$from its solvation shell, transport of $\mathrm{Li}^{+}$across the SEI, charge transfer at the SEI/graphite interface, and solid state diffusion along the graphene layers. Based on the impedance results shown in Figure 3, ohmic losses in LP30 and AR25 electrolytes were calculated to be 6.6 and $4.6 \mathrm{mV}$ under $372 \mathrm{~A} / \mathrm{kg}(\sim 2 \mathrm{~mA})$ constant specific current. Thus, differences in conductivity cannot explain the observed differences in practical specific charge. The last step can also be dismissed because lithium diffusion in the space between the graphene layers is independent of the electrolyte composition, given the presence of a protective film that prevents solvent co-intercalation following the formation cycles.

In the pursuit of what could be responsible for the differing galvanostatic behavior on THFIPB addition, we first focus on the significance of the SEI layer.

Figure 7 shows post-mortem SEM images of the anodes after 200 cycles at 1C rate in LP30 and AR25 electrolytes. The anode cycled in LP30 displays a continuous SEI that even exists between the graphite particles (Figure 7a). Some graphite particles are seen to be isolated from the neighboring particles by the SEI, and may therefore be assumed to be electronically isolated. In contrast, the anode from the AR25 cell shows a completely different SEI morphology. The film is not continuous between the particles (Figure 7c). Moreover, the SEI consists of two layers of granular morphology with the lower layer having smaller granules (Figure 7d). We suspect that the lower layer formed during the initial formation cycle, while the upper level is the product of prolonged cycling as can be explained by the higher irreversible charge "loss" (Figure 6c). It has been reported earlier that 
granular SEI is formed upon increased current density in the formation cycle [24]. Therefore we suggest that the SEI in the AR25 case may be formed at higher rate of EC reduction when THFIPB is added

Figure 7e confirms the presence of dendritic Li deposits in the LP30 electrolyte. These deposits are considered to be irreversible (i.e. electronically insulated) because the cells were kept at $1.5 \mathrm{~V}$ prior to SEM analysis. In addition, there are leaf-like structures visible underneath the SEI. We suspect that these structures are plated $\mathrm{Li}$, i.e. nuclei where dendrite growth begins. This assertion is reasonably consistent with the SEM characterization performed on the same samples after exposure to air; then we were unable to detect any of these structures. In contrast, the electrodes from the AR25 based cells showed no trace of Li deposits.

To understand the electrochemical basis for Li deposition, representative potential profiles for the $5^{\text {th }}$ cycle were plotted in Figure 8 with focus on the low-potential regions where the Li plating possibly occurs $\left(5^{\text {th }}\right.$ cycle was chosen as the representative cycle to avoid the effect of SEI formation and cell aging over repeated cycling). It is clear that the stage 2-to-stage 1 transition plateau shows almost no inclination on THFIPB addition, whereas it slopes downward in LP30. This suggests that the phase transition proceeds closer to equilibrium in AR25 cell which reduces the risk of metal plating due to the less probable local excursions to more negative potentials.

Moreover, although the cut-off potential was set to be $5 \mathrm{mV} v s$. Li, with the LP30 electrolyte rapid excursions in the potential profile down to $-2.3 \mathrm{mV}$ were observed, leading to Li metal deposition, as was also observed in the SEM micrographs (Figure 7e). Clearly, this is due to the sluggishness of the electronic control circuit, but this case illustrates the risks inherent to a practical system. The poor kinetics associated with the LP30 electrolyte increases the risk of Li-plating.

The voltage profile for the $5^{\text {th }}$ charge at $1 \mathrm{C}$ rate in Figure 8 also allows us to identify the origin of the observed higher charge with AR25 electrolyte. One easily estimates that the sum of the charge stored at the first and second intercalation plateaus are almost identical regardless of the THFIPB additive. However, the last intercalation stages differ from each other by their slopes, as discussed above. The 
difference in charge stored at this stage turns out to amount to the difference in galvanostatic capacities measured in the different electrolytes. This finding brings forward the hypothesis that we may now neglect the contribution of the de-solvation energy, if any, to the galvanostatic charge difference, otherwise we would expect a noticeable influence on the potential of the first and second stage transition plateaus, since the de-solvation energy is a quantity independent of the applied potential. An inevitable implication of this is that it is the SEI primarily responsible for the observed higher practical galvanostatic charge in the case of THFIPB addition, because from current understanding of the SEI, its composition may vary with applied potential and hence with the state of charge of the graphite electrode.

Figures $7 b$ and $7 d$ show the SEM micrographs of the edge planes of the electrodes cycled 200 times at $1 \mathrm{C}$ rate in LP30 and AR25 electrolytes, respectively. The edge planes of the graphite are clearly visible when the electrodes were cycled without THFIPB. On the other hand it is hardly possible to see beyond a thick SEI when THFIPB was added. It is recognized that $\mathrm{Li}^{+}$intercalation occurs mainly through the edge planes (and defects in the basal planes), therefore the thickness of the SEI on edge planes may limit the $\mathrm{Li}^{+}$transport rate across the SEI. However, the galvanostatic specific charges given in Figure 6b do not correlate well with the relative SEI thickness; instead the AR25 cell yields higher specific charge in galvanostatic mode, implying a modification in SEI chemistry on THFIPB addition that results in higher lithium conductivity, albeit thicker. This is indeed quite consistent with previous reports that suggest reduced $\mathrm{LiF}$ content in $\mathrm{SEI}$ upon anion receptor addition due to its strong affinity to negative charges [14]. It is also possible that the structure of the SEI is more porous for the AR25 electrolyte case, which would typically be compatible with irreversible gas-evolution reactions at higher potentials.

Based on observed differences in SEI formation kinetics and resulting morphological changes upon THFIPB addition, the question can now be asked whether the graphite performance following the SEI formation cycles can be assigned to the presence of THFIPB in the electrolyte. To answer this, SEIs were formed on graphitic anodes in the first two formation cycles in LP30 and AR25 electrolytes. The electrodes were then recovered from the cells, and the washed and dried electrodes were then 
reassembled in cells with a fresh separator and counter electrode in the other electrolyte, and cycled 200 times at the $1 \mathrm{C}$ rate. Figure 9 shows the specific charge versus cycle number. We note that, when the SEI is formed in LP30 and then the graphite is cycled in THFIPB electrolyte, the total capacity fade over repeated cycles can be neglected. On the other hand, when the electrode with the SEI formed in AR25 electrolyte was cycled in LP30 electrolyte, the capacity attained was about $50 \mathrm{Ah} / \mathrm{kg}$ lower than for the other case (>50 Ah/kg in the case of total capacity). It is now clear that the improved cycling stability is related to the presence of THFIPB during cycling, and not dependent on the initial formation of the SEI layer.

Figure 10 is a plot of specific charge as a function of charge rate during lithiation. Only the charge stored in the galvanostatic step is plotted in order to compare the kinetic performances. The cells were cycled at $0.2 \mathrm{C}, 1 \mathrm{C}, 2 \mathrm{C}, 5 \mathrm{C}, 10 \mathrm{C}$, and $0.2 \mathrm{C}$ following the SEI formation cycles at 10 and $50 \mathrm{~A} / \mathrm{kg}$. The AR25 cell has a higher capacity below $5 \mathrm{C}$, and once $5 \mathrm{C}$ is reached both cells attain the same practical capacity. The same phenomenon is also observed at 10C. After cycling at 10C, the cells were subjected to 10 cycles at $0.2 \mathrm{C}$ rate to investigate whether the electrodes had deteriorated during the high current regime. Both cells demonstrated stable performance and a similar specific charge. The AR25 cell reached a slightly lower specific charge compared to the $0.2 \mathrm{C}$ rate after the formation cycle, while the LP30 cell delivered the same specific charge to its initial performance at $0.2 \mathrm{C}$.

Figure 11a shows the galvanostatic specific charge $v s$. cycle number of the electrodes cycled at 1C rate at $0^{\circ} \mathrm{C}$ and $50^{\circ} \mathrm{C}$, respectively, following the SEI formation at room temperature in both electrolytes. It is evident from Figure 11 that the AR25 cell outperforms the LP30 electrolyte at both temperatures studied. In particular, we found that this is more significant at $0^{\circ} \mathrm{C}$ where the thermally activated processes, such as ionic transport in the electrolyte, de-solvation, and transport across the SEI, become more significant. Figures $11 \mathrm{~b}$ and $11 \mathrm{c}$ show the $5^{\text {th }}$ cycle potential profiles for both cells at $0^{\circ} \mathrm{C}$ and the high frequency impedance responses of LP30 and AR25 cells recorded at open circuit at $0^{\circ} \mathrm{C}$, respectively. According to the high frequency intersection with the real axis, the solution resistance of LP30 increases, in comparison to Figure 3, from $3.13 \mathrm{ohm}$ to $24 \mathrm{ohm}$ when the temperature decreased from room temperature to $0^{\circ} \mathrm{C}$, whereas the change is only from $2.5 \mathrm{ohm}$ to 3.9 
ohm in the case of AR25 electrolyte. An examination of the potential profiles shows that the onset potential of the first intercalation plateau is $\sim 20 \mathrm{mV}$ more positive in AR25 electrolyte, as indicated in Figure 11b. This difference is very well matching with the ohmic drop of $\sim 21.8 \mathrm{mV}$ in the electrolyte calculated using the data from the impedance measurement and the total current passing the system at $1 \mathrm{C}$ rate $(\sim 1.05 \mathrm{~mA})$. The last two intercalation stages are not well resolved in both electrolytes, however the charge stored is higher in AR25 as can be seen in Figure 11b. We may therefore attribute the higher galvanostatic charge to both lower solution resistance in AR25 and the differences in SEI chemistry as described above.

Rate performance of $\mathrm{Li}^{2} \mathrm{LiFePO}_{4}$ cells were also investigated with LP30 and AR25 electrolytes. Capacity retention, coulombic efficiency, and discharge curves of $\mathrm{Li} / \mathrm{LiFePO}_{4}$ cells with $\mathrm{LP} 30$ and AR25 in a voltage range of 2.5-4.2 V are given in Figure 12. The cell with AR25 demonstrates $>75 \%$ capacity retention while the cell with LP30 delivers only $~ 60 \%$ of the original capacity when the cells are discharged at 10C rate (Figure 12a). It should be noted that electrodes with $>80 \%$ capacity retention at $10 \mathrm{C}$ are considered as high rate by industrial conventions. The coulombic efficiency of the cell with AR25 is as high as the cell with LP30, indicating that AR25 cell does not have significant side reaction at the $\mathrm{LiFePO}_{4}$ surface (Figure 12b). It can be seen that AR25 cell has higher discharge polarization by $\sim 30 \mathrm{mV}$ and $\sim 50 \mathrm{mV}$ at $1 \mathrm{C}$ and $3 \mathrm{C}$ rates, respectively, although it delivers higher specific charge than LP30 cell does (Figure 12c). This observation, and also the good capacity retention at $10 \mathrm{C}$ rate, support the findings from the anode study that the electrolyte conductivity increases with AR addition, thus giving higher active material utilization within the porous electrode. It should be noted that the cathode is more than twice as thick as the anode, and therefore the performance is more sensitive towards electrolyte conductivity.

Power capability of the $\mathrm{Li} / \mathrm{LiFePO}_{4}$ half cells were investigated by the ASI analysis obtained by using a modified hybrid pulse power characterization (HPPC) test [20]. Results show that anion receptor addition decreases the cell impedance, especially at low and high DOD (Figure 13). It is likely that increased active material utilization and increased electrolyte conductivity result in lower polarization and thus lower cell ASI with AR25 electrolyte. 
Full cells were constructed with a graphite electrode (SLP30) and commercial $\mathrm{LiFePO}_{4}$. The cells were cycled at $1 \mathrm{C}$ rate in a voltage range of $2.50-3.55 \mathrm{~V}$ (Figure 14a). The results shown in Figure 14a are the cycles after the formation. During the initial charging, a specific charge capacity of 141 $\mathrm{mAh} / \mathrm{g}$ (with respect to the $\mathrm{LiFePO}_{4}$ cathode) was obtained for both LP30 and AR25 electrolytes, while the specific discharge capacity was slightly lower for the AR25 electrolyte $(93.8 \mathrm{mAh} / \mathrm{g}$ vs. 101 $\mathrm{mAh} / \mathrm{g}$ for LP30). The corresponding first cycle irreversible losses were thus $33.5 \%$ and $29.7 \%$ for AR25 electrolyte and LP30 electrolyte, respectively. These values are very close to the values obtained in the half cell (32\% and $26 \%$, respectively). The difference in the irreversible loss thus explains the lower discharge capacities for AR25 (Figure 13a), as in the full cell, the Li inventory is limited by the cathode. The fact that the cells delivered the same specific initial charge, implies good alignment of anode/cathode discs. As may be inferred from Fig. 14b, the voltage profile for the initial charging for the AR25 electrolyte is slightly lower compared to the profile for the LP30 electrolyte, while the charging profiles are overlapping for the $5^{\text {th }}$ cycles, in line with the half-cell results. Previous results showed a slightly improved capacity retention upon addition of THFIPB in electrolytes and cycling in full cells with MCMB anode and $\mathrm{LiNi}_{1 / 3} \mathrm{Mn}_{1 / 3} \mathrm{Co}_{1 / 3} \mathrm{O}_{2}$ cathode, with electrolytes containing $3 \mathrm{wt} \%$ THFIPB in $1.2 \mathrm{M} \mathrm{LiPF}_{6}$ 3:7 EC:EMC [13]. The interfacial impedance was reported to be lower, and a slightly improved stability was observed after 200 cycles at 1C. The authors did however not report on the irreversible losses [13]. Based on the results obtained in the current work, however, the slightly lower coulombic efficiency, both for the formation cycle, and also during the subsequent cycles (Figure 6c) for the electrolyte containing THFIPB, masks the potential benefits of this additive observed for the half cells.

\section{Conclusion}

THFIPB is proposed to be used to improve the electrochemical performance of an SLP30 graphite electrode with respect to the total specific charge and galvanostatic specific charge. A stable SEI forms on a graphite electrodes in the presence of THFIPB. THFIPB modifies the SEI and its morphology on the SLP30 graphite and renders the SEI a better $\mathrm{Li}^{+}$conductor. THFIPB addition can be used to control the SEI formation and prevent insulating films from developing, as experienced in 
the LP30 electrolytes. THFIPB is a useful additive in terms of practical galvanostatic charge and solution resistance, especially for low temperature operations. THFIPB is also compatible with commercial $\mathrm{LiFePO}_{4}$ cathode and decreases the $\mathrm{Li} / \mathrm{LiFePO}_{4}$ cell impedance. It can be used in Graphite/ $\mathrm{LiFePO}_{4}$ full cells without inflicting voltage penalty, while high irreversible charge in the first charge renders low discharge capacity.

\section{Acknowledgements}

This work was funded by the Norwegian University of Science and Technology. The Paul Scherrer Institute in Switzerland is acknowledged for supporting the experimental work.

\section{References}

[1] W. Märkle, W. Tran, D. Goers, M. Spahr and P. Novák, Carbon, vol. 37, pp. 2727-2732, 2009.

[2] J. Gnanaraj, R. Thompson, S. laconatti, J. DiCarlo and K. Abraham, Electrochemical solid state letters, vol. 8, no. 2, pp. A128-A132, 2005.

[3] E. Peled, J. Electrochem. Soc, vol. 126, no. 12, pp. 2047-2051, 1979.

[4] K. Xu and A. Cresce, J. Mater. Chem., vol. 21, pp. 9849-9864, 2011.

[5] P. Verma, P. Maire and P. Novák, Electrochimica Acta, vol. 55, pp. 6332-6341, 2010.

[6] K. Xu, A. Cresce and U. Lee, Langmuir, vol. 26, no. 11, pp. 11538-11543, 2010.

[7] D. Aurbach, Y. Talyosef, B. Markovsky, E. Markevixh, E. Zinigrad, L. Asraf, S. Gnanaraj and H. Kim, Electrochimica Acta, vol. 50, no. 2, pp. 247-254, 2004.

[8] X. Sun, H. Lee, X. Yang and J. McBreen, J. Electrochem. Soc., vol. 146, no. 10, pp. 3655-3659, 1999.

[9] H. Lee, X. Yang and J. McBreen, J. Electrochem. Soc., vol. 145, no. 8, pp. 2813-2818, 1998.

[10] W. West, J. Whitacre, N. Leifer, S. Greenbaum, M. Smart, B. Ratnakumar, M. Blanco and S. Narayanan, J. Electrochem. Soc., vol. 154, no. 10, pp. A929-A936, 2007.

[11] X. Sun, H. Lee, X. Yang and J. McBreen, J. Electrochem. Soc, vol. 149, no. 3, pp. A355-A359, 2002.

[12] Z. Chen and K. Amine, J. Electrochem. Soc., vol. 153, no. 6, pp. A1221-A1225, 2006. 
[13] Y. Qin, Z. Chen, H. Lee, X. Yang and K. Amine, J. Phys. Chem. (C), vol. 114, pp. 15202-15206, 2010.

[14] M. Herstedt, M. Stjerndahl, T. Gustafsson and K. Edström, Electrochem. Commun., vol. 5, pp. 467-472, 2003.

[15] Z. Chen and K. Amine, Electrochem. Commun, vol. 9, pp. 703-707, 2007.

[16] X. Sun, H. Lee, X. Yang and J. McBreen, Electrochem. Solid-State Lett., vol. 6, no. 2, pp. A43-A46, 2003.

[17] S. Sloop, J. Pugh, S. Wang, J. Kerr and K. Kinoshita, Electrochem. Solid-State Lett., vol. 4, no. 4, pp. A42-A44, 2001.

[18] Z. Chen and K. Amine, J. Electrochem. Soc., vol. 156, no. 8, pp. A672-A676, 2009.

[19] A. Cresce, M. Gobet, O. Borodin, J. Peng, S. Russell, E. Wikner, A. Fu, L. Hu, H. Lee, Z. Zhang, X. Yang, S. Greenbaum, K. Amine and K. Xu, J. Phys. Chem. C, vol. 119, pp. 27255-27264, 2015.

[20] B. Long, S. Rinaldo, K. Gallagher, D. Dees, S. Trask, B. Polzin, A. Jansen, D. Abraham, J. Bareno and J. Croy, J. Electrochem. Soc., vol. 163, no. 14, pp. A2999-A3009, 2016.

[21] R. Imhof and P. Novak, J. Electrochem. Soc., vol. 145, no. 4, pp. 1081-1087, 1998.

[22] M. Nie, D. Chalasani, D. Abraham, Y. Chen, A. Bose and B. Lucht, J. Phys. Chem. C, vol. 117, pp. 1257-1267, 2013.

[23] J. Harris, A. Timmons, D. Baker and C. Monroe, Chem. Phys. Lett., vol. 485, pp. 265-274, 2010.

[24] W. Märkle, C. Lu and P. Novák, J. Electrochem. Soc., vol. 158, no. 12, pp. A1478-A1482, 2011.

[25] R. Imhof and P. Novák, J. Electrochem. Soc., vol. 145, no. 4, pp. 1081-1087, 1998.

[26] Y. Yamada, Y. Koyama, T. Abe and Z. Ogumi, J. Phys. Chem. C, vol. 113, pp. 8948-8953, 2009.

[27] D. Aurbach, B. Markovsky, A. Weissman, E. Levi and Y. Ein-Eli, Electrochim. Acta, vol. 45, pp. 6786, 1999.

[28] T. Ohzuku, Y. Iwakoshi and K. Sawai, J. Electrochem. Soc., vol. 140, no. 9, pp. 2490-2498, 1993. 


\section{Figures}

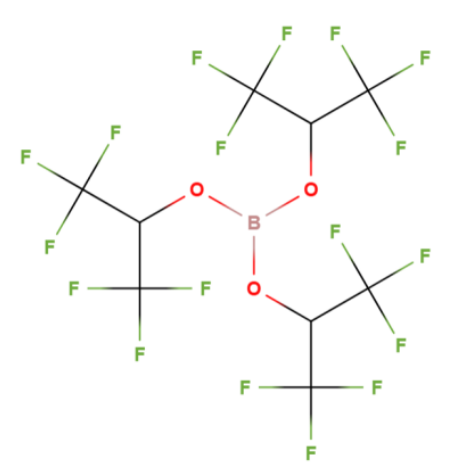

Figure 1. Molecular structure of THFIPB.
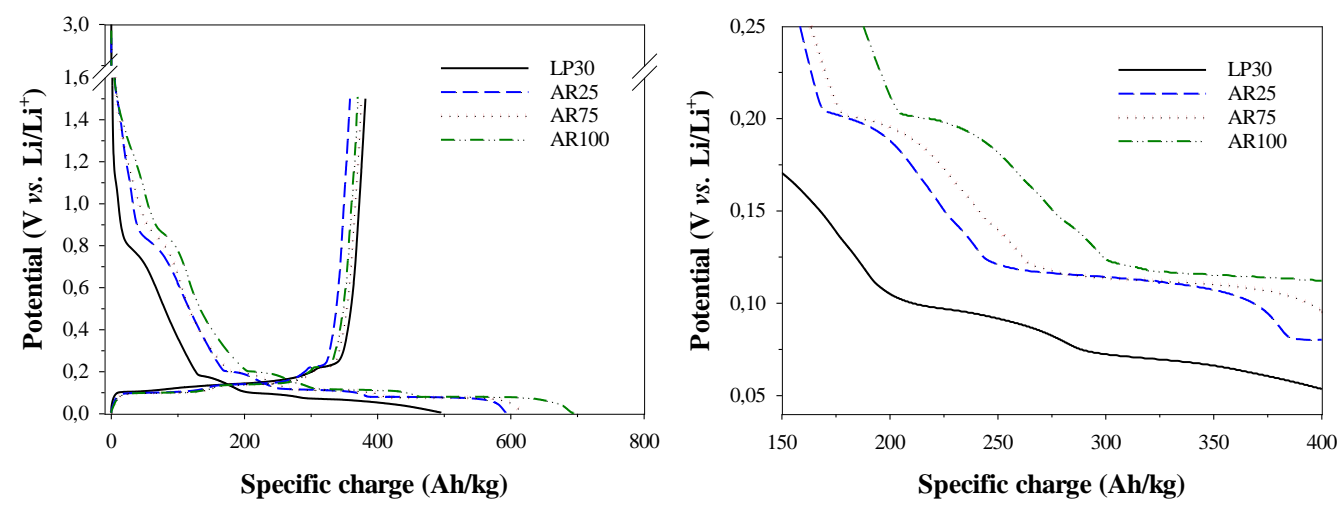

Figure 2. a) Potential profiles of Li/SLP30 half cells as a function of specific charge for the first lithiation in LP30, AR25, AR75, and AR100. b) Expanded view of the first lithiation plateaus. 


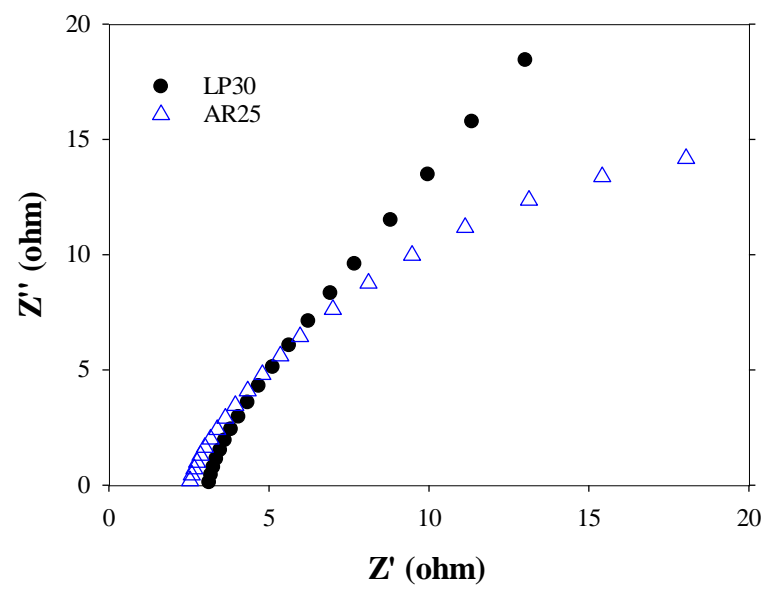

Figure 3. Electrochemical impedance spectra of Li/SLP30 half cells in LP30 and AR25. Notice that a two-electrode cell design was used where Li foil served as both counter and reference electrode. 

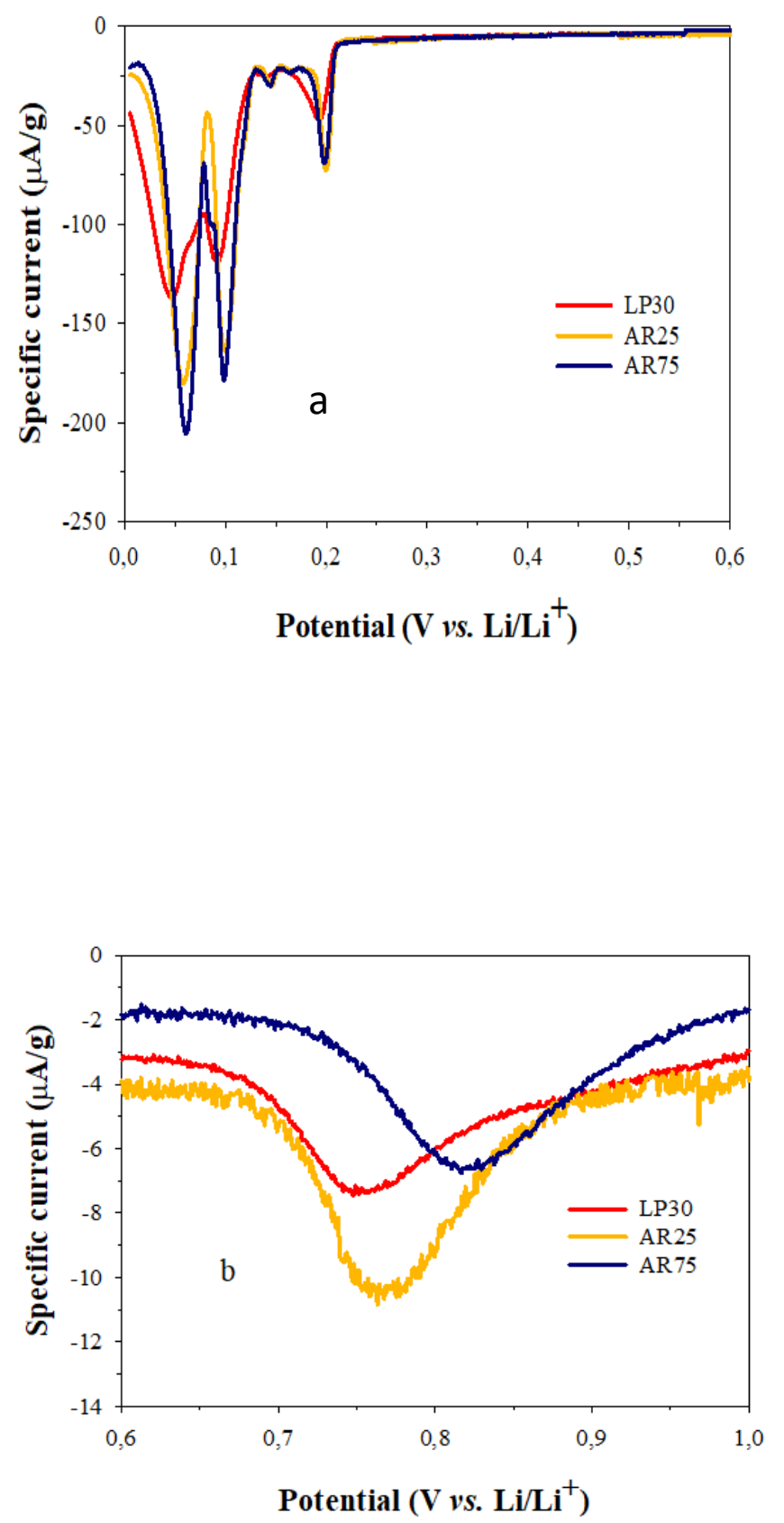

Figure 4. a) Linear sweep voltammograms (LSVs) obtained in LP30, AR25 and AR75 electrolyte at $10 \mu \mathrm{Vs}^{-1}$ on SLP30 graphite electrode. b) Close up of the LSVs in the potential range for solvent reduction. 


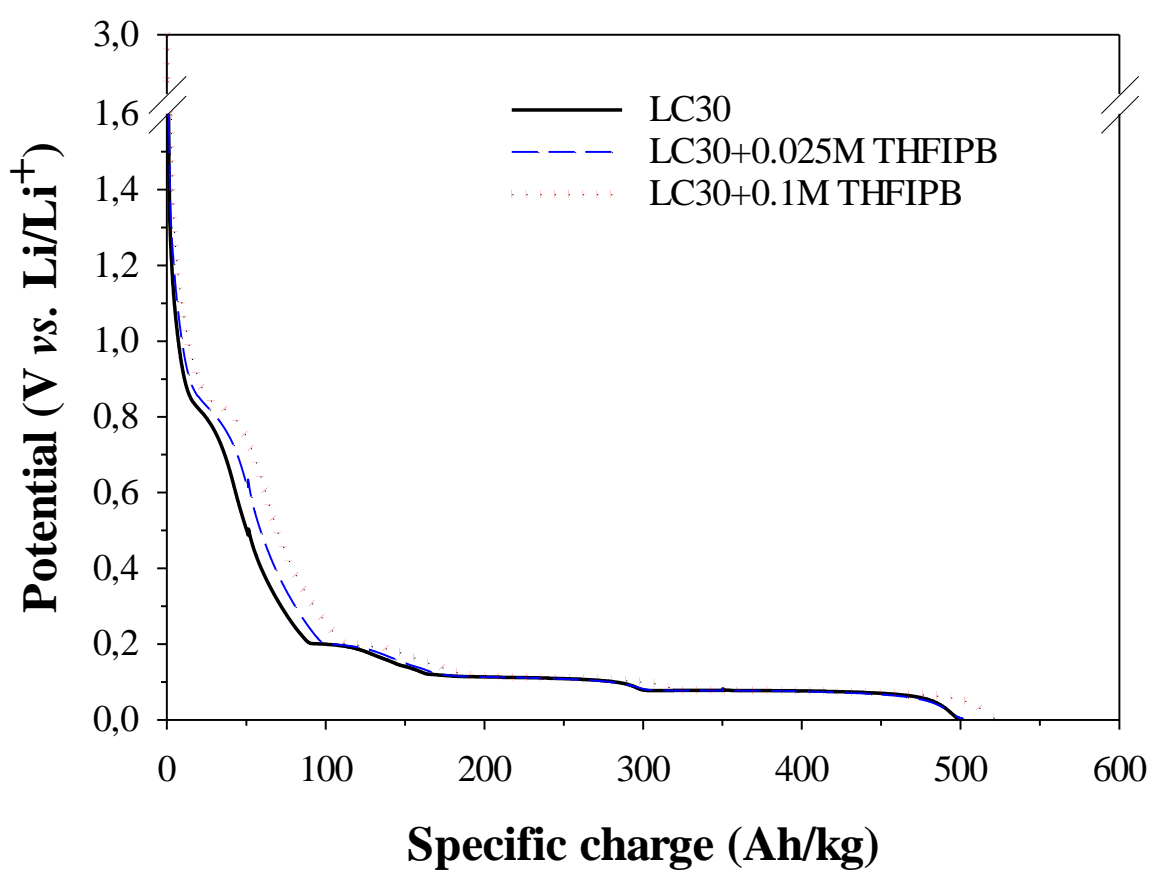

Figure 5. Potential profiles of Li/SLP30 half cells as a function of specific charge for the first lithiation in neat LC30 (solid), LC30 with $0.025 \mathrm{M}$ THFIPB (dashed), and LC30 with $0.1 \mathrm{M}$ THFIPB (dotted) additive. 

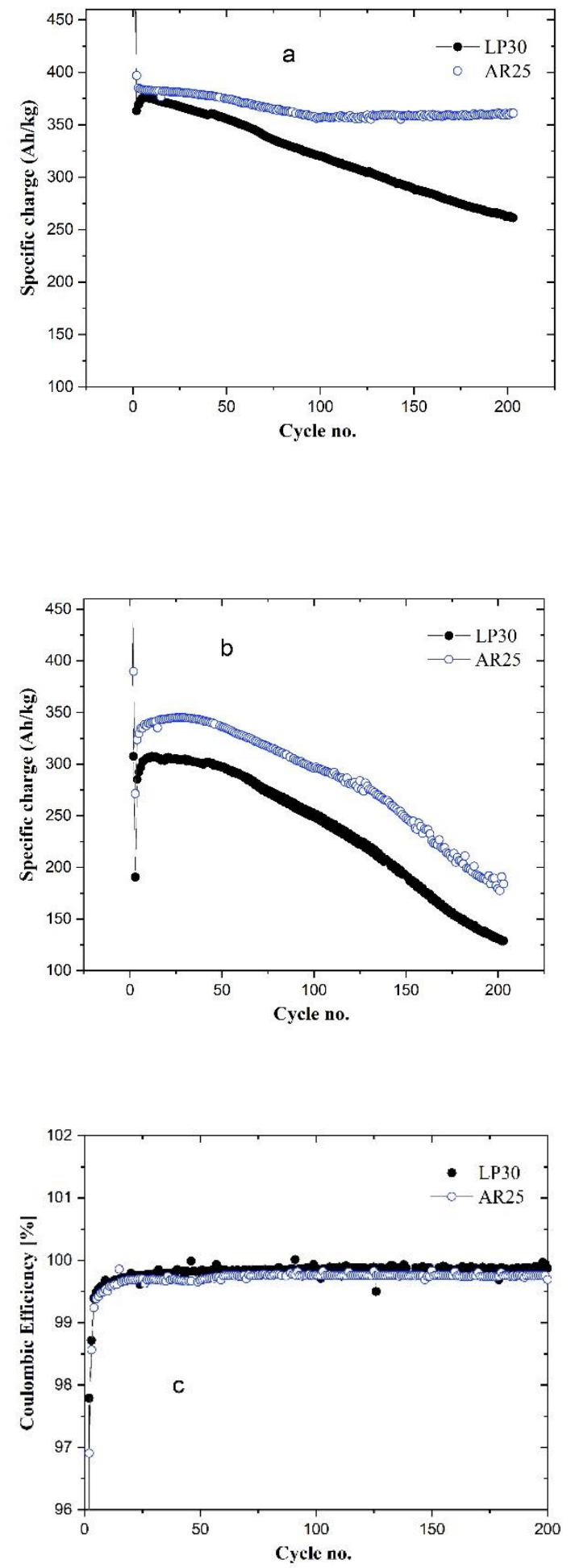

Figure 6. Cycling performance of Li/SLP30 half cells cycled in LP30 and AR25 under a constant specific current of $372 \mathrm{~A} / \mathrm{kg}$ (1C rate) following the formation cycles. a) Total specific charge, b) galvanostatic specific charge, c) Coulombic efficiency. 

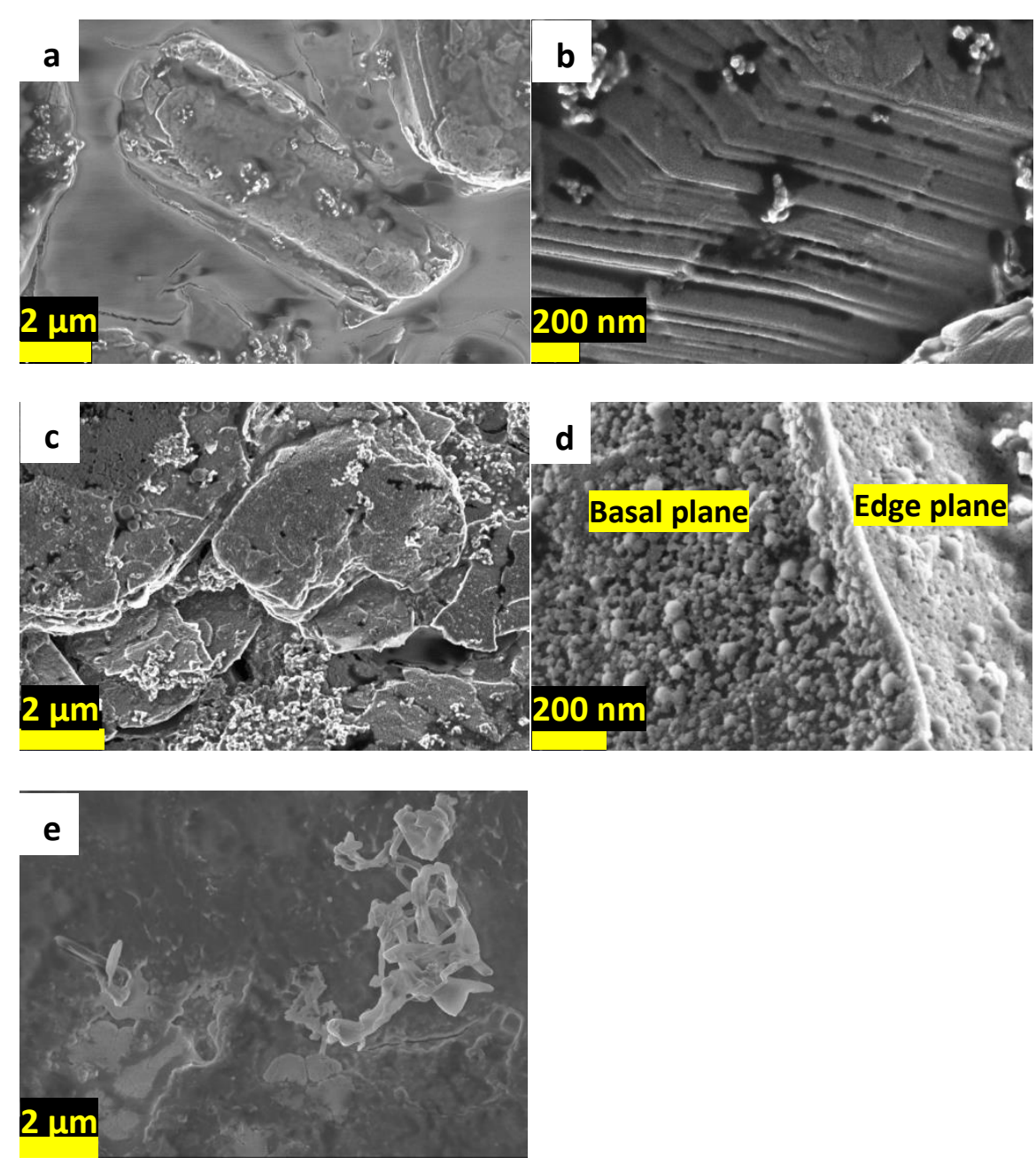

Figure 7. SEM images of SLP30 anodes cycled 200 times under a constant specific current of $372 \mathrm{~A} / \mathrm{kg}$ (1C rate) following the formation cycles in a-b-e) LP30 and c-d) AR25. Li deposits in the form of dendrites are seen in 'e’. 


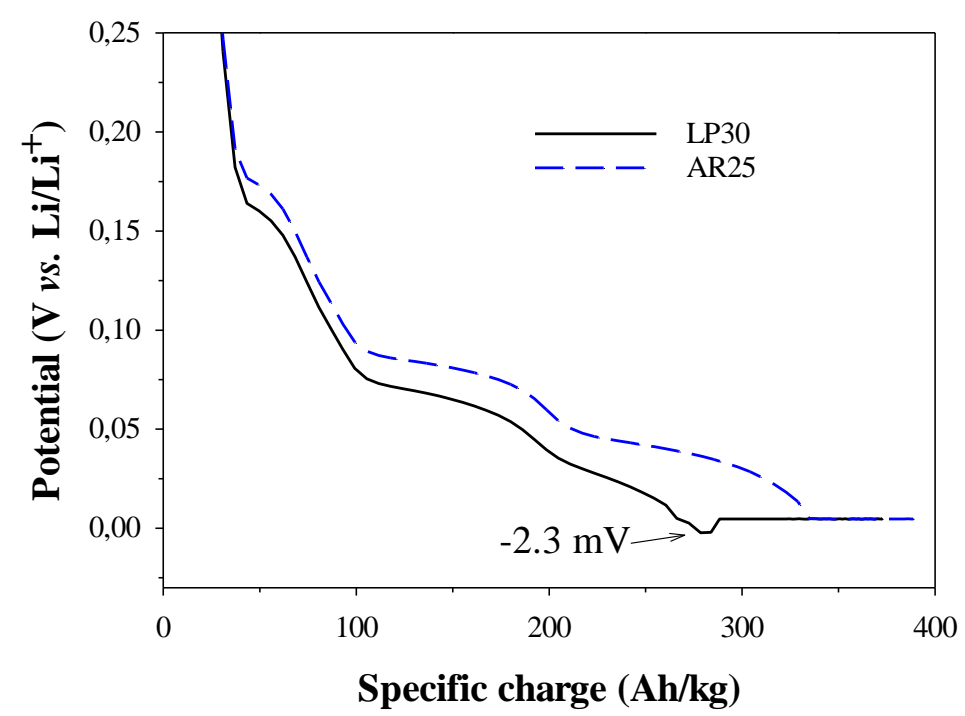

Figure 8. Potential profiles of Li/SLP30 half cells as a function of specific charge for the fifth cycle in LP30 (solid line) and AR25 (dashed line) electrolytes under a constant specific current of $372 \mathrm{~A} / \mathrm{kg}$ (1C rate) following the formation cycles. 

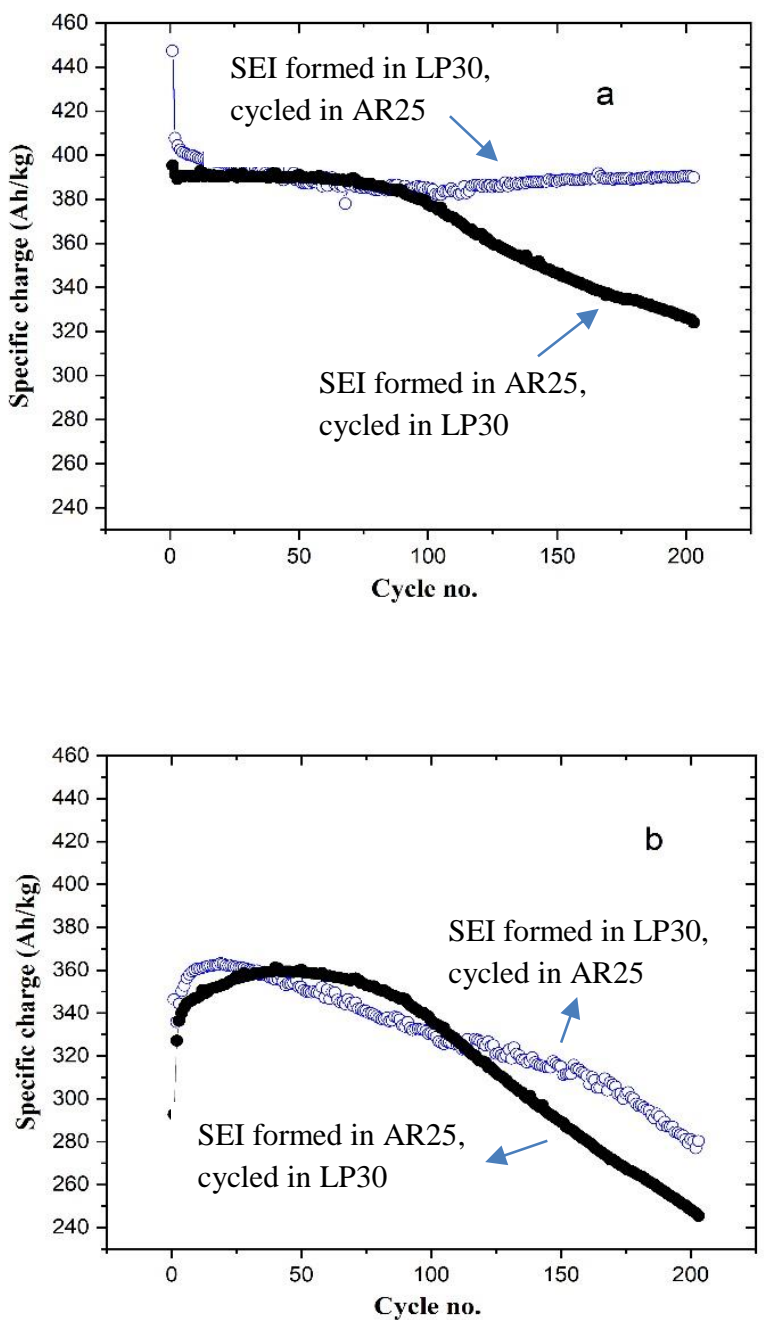

Figure 9. Cycling performance of Li/SLP30 half cells under a constant specific current of $372 \mathrm{~A} / \mathrm{kg}$ (1C rate) in LP30 and AR25. Formation cycles were completed in LP30 and the subsequent cycles were completed in AR25 and vice versa, as indicated in the figures. a) Total specific charge, b) galvanostatic specific charge. 


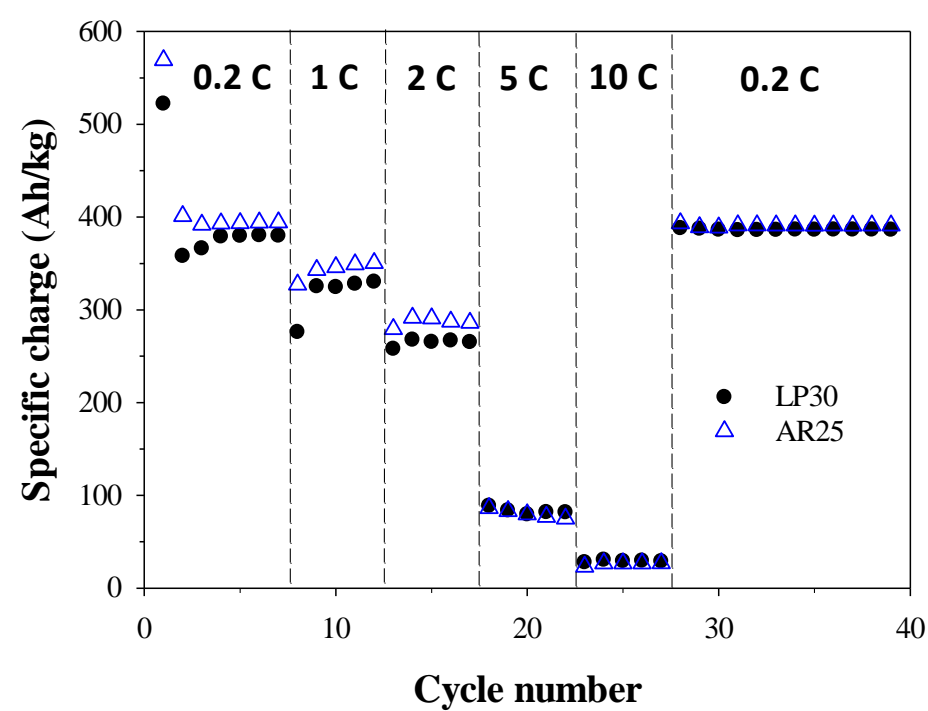

Figure 10. Rate performance of Li/SLP30 half cells under various specific currents ranging from 74.4 $\mathrm{A} / \mathrm{kg}(0.2 \mathrm{C}$ rate) to 3’720 $\mathrm{A} / \mathrm{kg}$ (10C rate) in LP30 and AR25. 

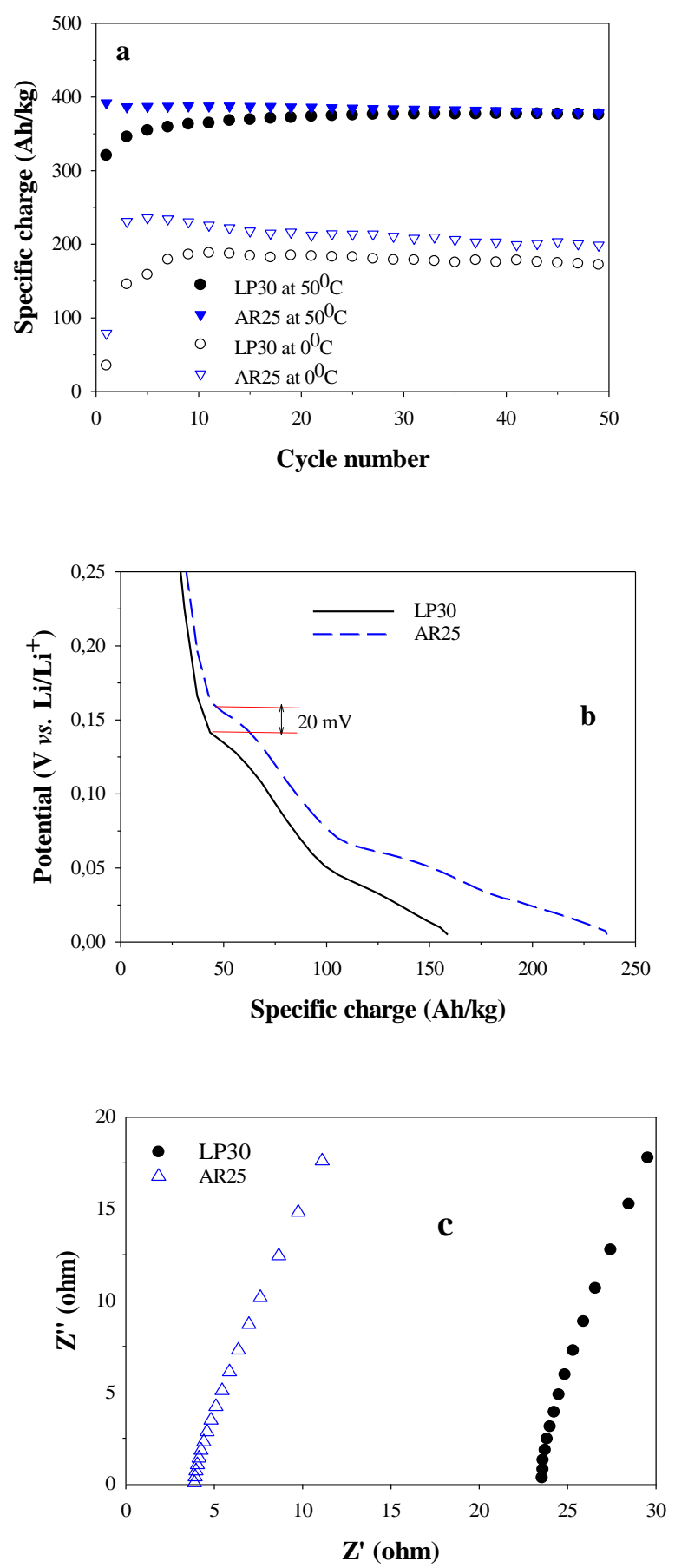

Figure 11. Performance of Li/SLP30 half cells in LP30 and AR25. a) Galvanostatic specific charge under a constant specific current of $372 \mathrm{~A} / \mathrm{kg}$ (1C rate) following the formation cycles at $0^{\circ} \mathrm{C}$ and $\left.50^{\circ} \mathrm{C}, \mathbf{b}\right)$ potential profiles as a function of specific charge for the fifth lithiation at $0^{\circ} \mathrm{C}$, and $\mathbf{c}$ ) electrochemical impedance spectra at $0^{\circ} \mathrm{C}$, where $\mathrm{Li}$ foil served as both counter and reference electrode in a two-electrode cell design. 

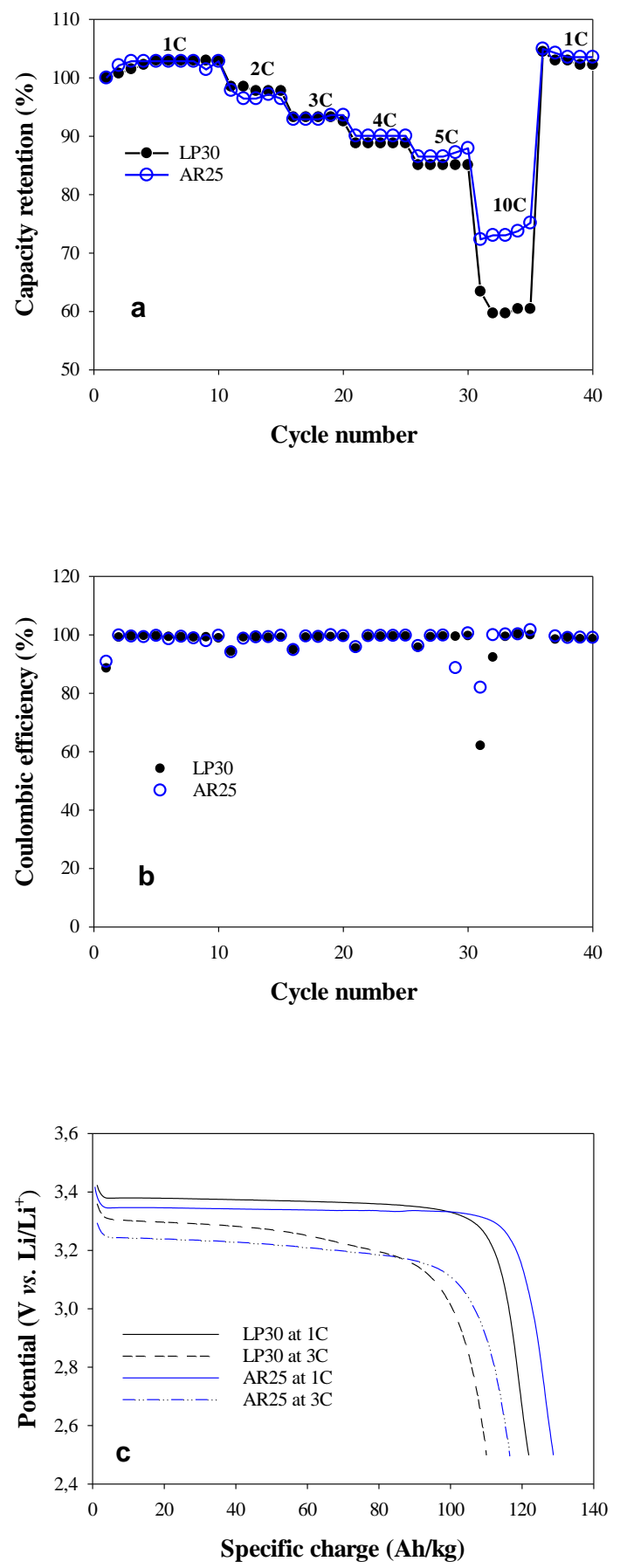

Figure 12. Rate performance of $\mathrm{Li} / \mathrm{LiFePO}_{4}$ half cells in $\mathrm{LP} 30$ and $\mathrm{AR} 25$. a) Capacity retention vs. cycle number, b) corresponding coulombic efficiency, c) discharge profiles at selected rates. 


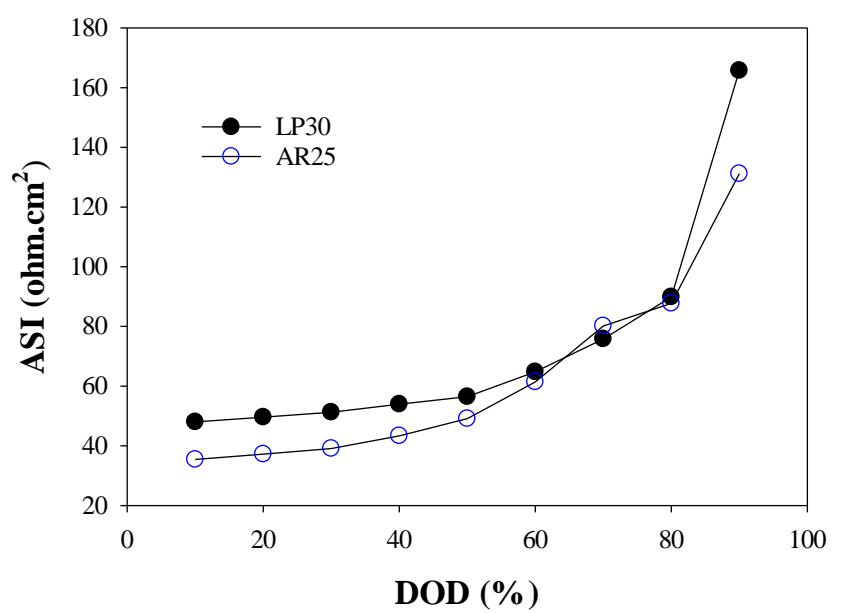

Figure 13. Discharge ASI vs. depth of discharge for $\mathrm{Li}^{2} / \mathrm{LiFePO}_{4}$ half cells. 


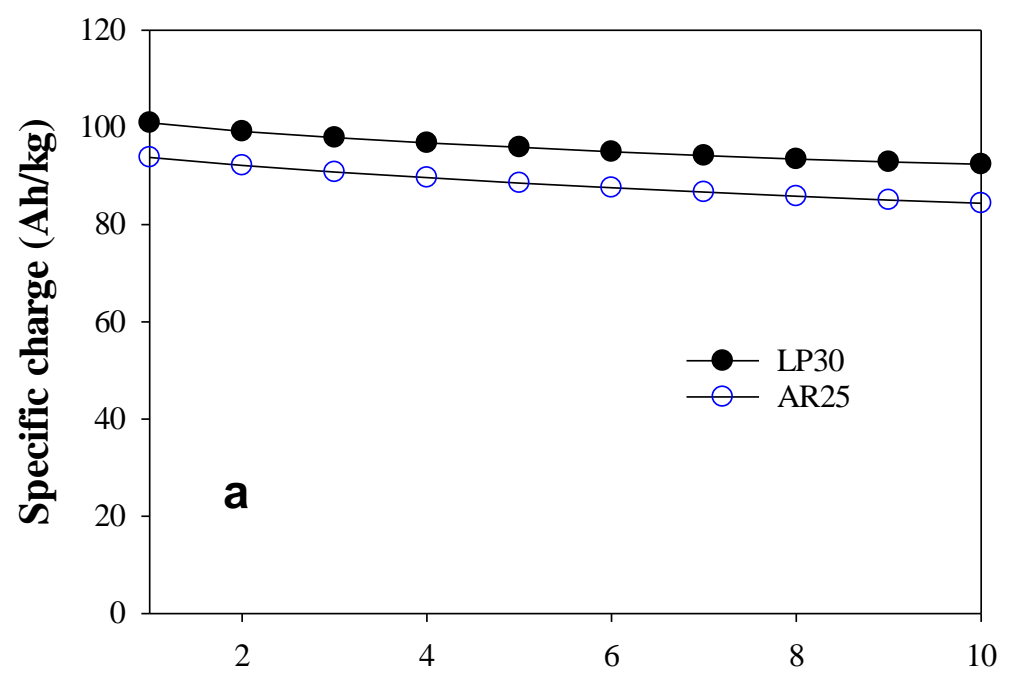

Cycle number

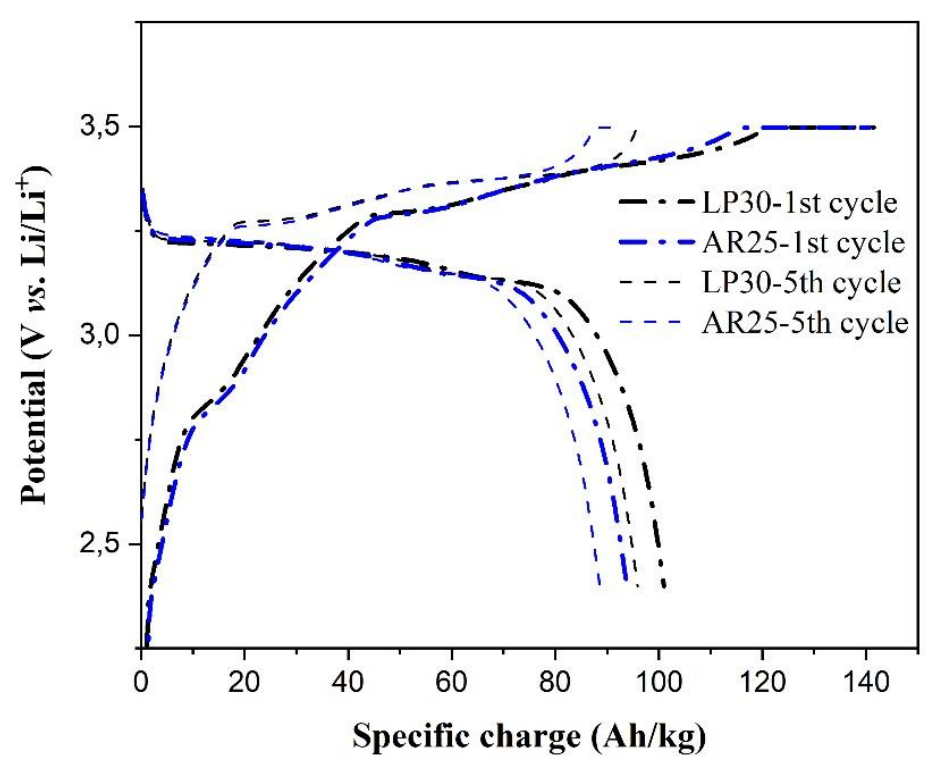

Figure 14. Cycling performance of Graphite/LiFePO 4 full cells in LP30 and AR25. a) Specific charge vs. cycle number, b) charge/discharge profiles for the first and fifth cycles. 


\section{Figure Captions}

Figure 1. Molecular structure of THFIPB.

Figure 2. a) Potential profiles of Li/SLP30 half cells as a function of specific charge for the first lithiation in LP30, AR25, AR75, and AR100 b) Expanded view of the first lithiation plateaus.

Figure 3. Electrochemical impedance spectra of Li/SLP30 half cells in LP30 and AR25. Notice that a two-electrode cell design was used where Li foil served as both counter and reference electrode.

Figure 4. a) Linear sweep voltammograms (LSVs) obtained in LP30, AR25 and AR75 electrolyte at $10 \mu \mathrm{Vs}^{-1}$ on SLP30 graphite electrode. b) Close up of the LSVs in the potential range for solvent reduction.

Figure 5. Potential profiles of Li/SLP30 half cells as a function of specific charge for the first lithiation in neat LC30 (solid), LC30 with 0.025M THFIPB (dashed), and LC30 with 0.1M THFIPB (dotted) additive.

Figure 6. Cycling performance of Li/SLP30 half cells cycled in LP30 and AR25 under a constant specific current of $372 \mathrm{~A} / \mathrm{kg}$ (1C rate) following the formation cycles. a) Total specific charge, b) galvanostatic specific charge, c) coulombic efficiency.

Figure 7. SEM images of SLP30 anodes cycled 200 times under a constant specific current of $372 \mathrm{~A} / \mathrm{kg}$ (1C rate) following the formation cycles in a-b-e) LP30 and c-d) AR25. Li deposits in the form of dendrites are seen in 'e`.

Figure 8. Potential profiles of Li/SLP30 half cells as a function of specific charge for the fifth cycle in LP30 (solid line) and AR25 (dashed line) electrolytes under a constant specific current of $372 \mathrm{~A} / \mathrm{kg}$ (1C rate) following the formation cycles.

Figure 9. Cycling performance of Li/SLP30 half cells under a constant specific current of $372 \mathrm{~A} / \mathrm{kg}$ (1C rate) in LP30 and AR25. Formation cycles were completed in LP30 and the subsequent cycles 
were completed in AR25 and vice versa, as indicated in the figures. a) Total specific charge,

b) galvanostatic specific charge.

Figure 10. Rate performance of Li/SLP30 half cells under various specific currents ranging from 74.4 $\mathrm{A} / \mathrm{kg}\left(0.2 \mathrm{C}\right.$ rate) to $3^{\prime} 720 \mathrm{~A} / \mathrm{kg}(10 \mathrm{C}$ rate) in $\mathrm{LP} 30$ and $\mathrm{AR} 25$.

Figure 11. Performance of Li/SLP30 half cells in LP30 and AR25. a) Galvanostatic specific charge under a constant specific current of $372 \mathrm{~A} / \mathrm{kg}$ (1C rate) following the formation cycles at $0^{\circ} \mathrm{C}$ and $\left.50^{\circ} \mathrm{C}, \mathbf{b}\right)$ potential profiles as a function of specific charge for the fifth lithiation at $0^{\circ} \mathrm{C}$, and c) electrochemical impedance spectra at $0^{\circ} \mathrm{C}$, where $\mathrm{Li}$ foil served as both counter and reference electrode in a two-electrode cell design.

Figure 12. Rate performance of $\mathrm{Li} / \mathrm{LiFePO}_{4}$ half cells in $\mathrm{LP} 30$ and $\mathrm{AR} 25$. a) Capacity retention vs. cycle number, b) corresponding coulombic efficiency, $\mathbf{c}$ ) discharge profiles at selected rates.

Figure 13. Discharge ASI vs. depth of discharge for $\mathrm{Li}^{2} / \mathrm{LiFePO}_{4}$ half cells.

Figure 14. Cycling performance of Graphite/LiFePO 4 full cells in LP30 and AR25. a) Specific charge vs. cycle number, b) charge/discharge profiles for the first and fifth cycles. 